\title{
Characterization of Boiling Phenomena during Laboratory-Scale Forced Convection Quenching
}

\author{
Roberto Cruces, Bernardo Hernández, Francisco Novas \\ Depto. de Ingeniería Metalúrgica, Facultad de Química, Universidad Nacional Autónoma de México \\ Cd. Universitaria, Ciudad de México, México \\ rcr_2621@hotmail.com; bernie@unam.mx
}

\begin{abstract}
An experimental investigation was conducted to correlate heat extraction with boiling phenomena at the liquid-probe interface during forced convective quenching of a steel probe in a laboratory-scale facility. A conical-end probe made of AISI 304 stainless steel instrumented with two type-K thermocouples was rapidly cooled from $850{ }^{\circ} \mathrm{C}$ in water at $60^{\circ} \mathrm{C}$, flowing with a free-stream velocity of $0.2 \mathrm{~m} / \mathrm{s}$. Bubble formation, growth and detachment at the probe surface was recorded with a high-speed video camera. Using the experimental cooling curves measured with the sub-surface thermocouple, the surface heat flux was estimated by solving a onedimensional inverse heat conduction problem (IHCP) without phase change. The inverse boiling curve obtained showed that the maximum peak on heat extraction was reached during the nucleate boiling stage and is associated with the time at which the wetting front passed though the thermocouple axial location. From image analysis, two regions can be distinguished as the wetting front travels through the probe: the wetting front, formed by small bubbles that grew rapidly and coalesced due to the large bubble population; and a region trailing the wetting front, where the size, population and dynamic behavior of the bubbles was quite different. These bubbles grew conserving a spheroidal shape until they reached their maximum size; when they were decreasing, a concave deformation was observed at the interface due to condensation caused by the quench media rewetting the surface and, finally, the bubble departed from the probe surface, collapsing in the bulk flow near the probe surface.
\end{abstract}

Keywords: Quenching, Boiling Phenomena, Bubble Dynamics, Heat Extraction.

\section{Introduction}

Since early times, steel quenching has played a significant role in the growth of civilizations throughout the world [1]. This heat-treating process usually requires heating the part to a high temperature, holding it at that temperature for a given time (an operation known as austenization for steels), and rapidly cooling the part to produce a particular microstructure, thus modifying its mechanical properties [2]. Quenching of steel parts is a complex phenomenon due to the interaction among the thermal, microstructural and mechanical fields during cooling [3]. In particular, heat extraction during immersion quenching in volatile media such as water, oil or aqueous polymer solutions, is accompanied by different boiling phenomena on the surface of the solid. In order of higher to lower probe surface temperature, three heat transfer regimes can be distinguished: (a) vapor film, in this stage heat extraction, occurs by conduction and radiation through a vapor film formed around the solid surface; (b) nucleate boiling, this stage begins when the vapor film collapses and liquid comes back in contact with the probe (known as "rewetting"), and is characterized by high heat extraction rates due to the continuous nucleation and bubble growth; and (c) pure convection (either natural or forced), which results in relatively low cooling rates [4]. To improve the understanding of the boiling mechanisms, in particular during the nucleate boiling stage, the characteristics of the bubbles and their dynamic behavior must be studied. Most of the research conducted in this field has been carried out through heating experiments [5-10] and provide information related to bubble parameters such as size distribution, departure diameter, lifetime, growth rate, etc., as function of system variables such as heat flux, pressure, subcooling or quenchant velocity.

The motivation of this investigation is to characterize bubble dynamic behavior during quenching of probes at a laboratory-scale facility to, eventually, evaluate boiling models proposed in the specialized literature and select the most appropriate one. As a first step, we conducted a study based on cooling curve analysis and image analysis, which is reported in this paper. 


\section{Experimental}

The laboratory-scale device is shown in Fig. 1 [11]. It consists of a tank connected to a $1 / 2$ HP pump that draws water through a flowmeter (Blue White, model F420, scale: 0-100 L/min) to feed a $45 \mathrm{~mm}$-I.D. plexiglass tube. The tube is 1.80 $\mathrm{m}$ long and was placed concentrically with respect to a $9 \mathrm{~cm} \times 9 \mathrm{~cm} \times 20 \mathrm{~cm}$ glass container (located at the top of the tube) that is filled with water to prevent optical distortion during video recordings. The secondary container above, captured the overflow and returned it to the tank. A vertical split tube furnace was used for heating up the probe to a temperature $10^{\circ} \mathrm{C}$ above the initial test temperature to ensure that it had the initial treatment temperature when it was placed into the plexiglass tube. To transport the probe from the heating position to the cooling position (probe end was $10 \mathrm{~cm}$ from the top of the tube), it was attached to a moving spreader to facilitate its transportation.

The quenchant was water at $60{ }^{\circ} \mathrm{C}$ with a free-stream velocity of $0.2 \mathrm{~m} / \mathrm{s}$; the initial probe temperature was $850^{\circ} \mathrm{C}$. Water was heated with an electrical resistance heater submerged in the tank and its temperature was monitored at the outlet of the tube during the test. The experiment was repeated five times to assure the reproducibility of the data.

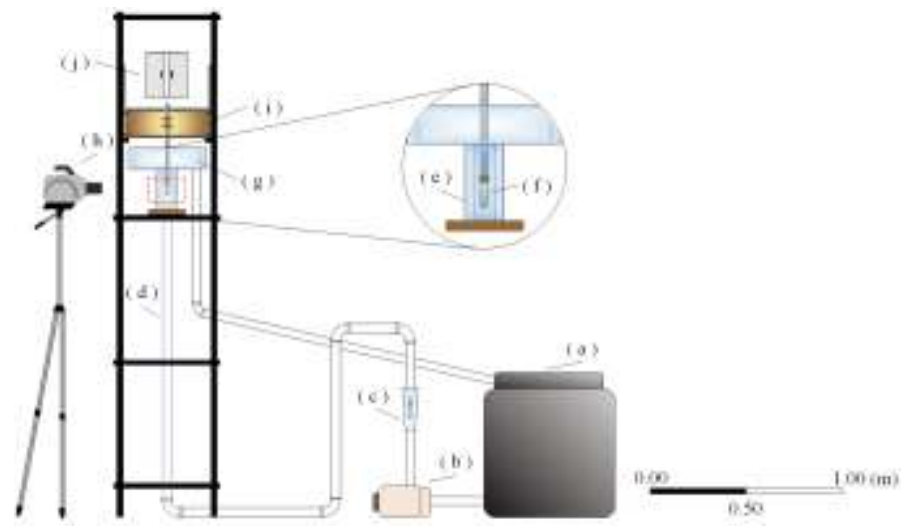

Fig. 1: Experimental set-up: (a) storage tank, (b) pump, (c) rotameter, (d) plexiglass tube, (e) glass container, (f) probe, (g) secondary container, (h) high-speed video camera, (i) moving spreader and (j) vertical split tube furnace.

The experiments were carried out with a $12.7 \mathrm{~mm}$-dia. cylindrical conical-end probe (refer to Fig. 2). The probe was machined from AISI 304 stainless steel bars and instrumented with two Type K (chromel-alumel) thermocouples with a nominal diameter of $1.58 \mathrm{~mm}$ and an accuracy of $0.7^{\circ} \mathrm{C}$. The thermocouples were located at mid-height of the probe: TC1 at $2.38 \mathrm{~mm}$ from the probe surface and TC2 at the geometric center of the probe. Before each test, the probe was grounded with abrasive silicon carbide paper (600 Standard ANSI grit).

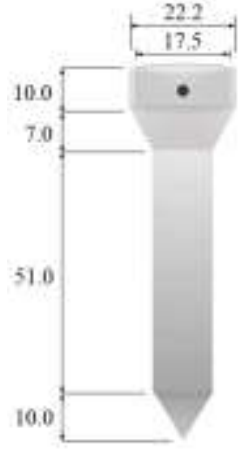

(a)

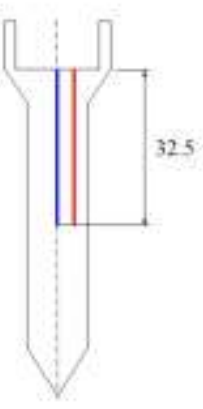

(b)

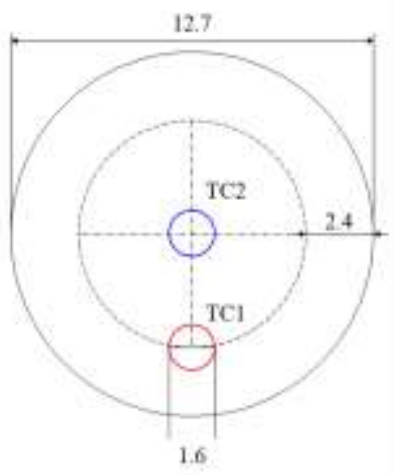

(c)

Fig. 2: Probe geometry: (a) probe dimensions, (b) thermocouple holes and (c) top view showing thermocouple distribution and labelling. Dimensions are in $\mathrm{mm}$.

A USB Data Acquisition Module (IOTECH Personal Daq/50 Series) connected to a portable computer was used for recording the temperature-time history of the two thermocouples. The software package Personal DaqView 2.2.1 was used 
to control the data acquisition operation; the sampling rate was set to $10 \mathrm{~Hz}$. The measured local cooling curves were smoothed (using the negative exponential smoothing algorithm implemented in SigmaPlot v 12.3) to reduce electrical noise.

Videos were recorded using a high-speed video camera (Phantom v1211 from Vision Research Inc.) placed in front of the test position, $30 \mathrm{~cm}$ from the outer wall of the tube. Videos were edited (to enhance the quality of the bubble contour) and analyzed using the motion analysis software Tracker v. 4.11. This software tracks the outline of the bubbles generating a spline by using control points that were fit to the bubble contour. The software computes statistics such as the location of the center of gravity, the perimeter of the contour and the area contained within the spline.

\section{Mathematical Model}

The smoothed thermal history measured with the sub-surface thermocouple (TC1) was used as input in an in-house code developed to solve the IHCP assuming 1D heat flow (radial direction) through a slice containing the thermocouples, as schematically shown in Fig. 3(a). The IHCP model was solved using the function specification method (FSM) [12], coupled with an implicit finite-difference scheme; an example of the nodal distribution is shown in Fig. 3(b).

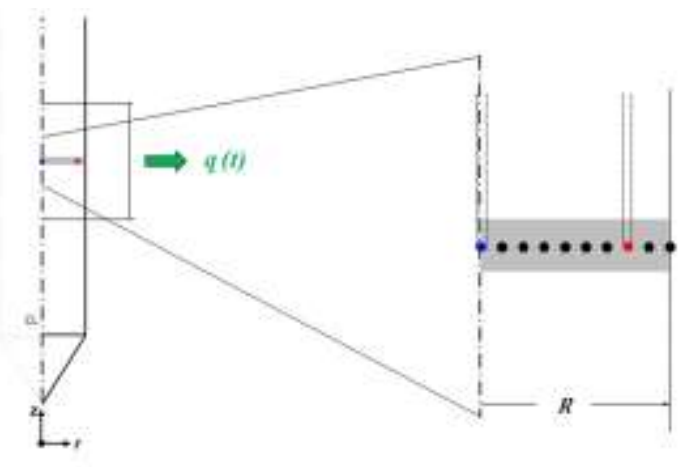

(a)

(b)

Fig. 3: (a) Schematic representation of the domain used to solve the IHCP and (b) finite difference nodes.

The system was considered as a continuous solid (the discontinuity in the material due to the insertion of thermocouples was ignored). Since the probe was made with an austenitic stainless steel no phase transformations took place upon cooling and therefore there is no presence of internal thermal sources. Thus, the mathematical formulation of the IHCP is given by the following governing equation, boundary conditions and initial condition:

$$
\begin{aligned}
& \frac{1}{r} \frac{\partial}{\partial r}\left(k r \frac{\partial T}{\partial r}\right)=\rho C_{p} \frac{\partial T}{\partial t} \quad 0 \leq r \leq R \quad t>0 \\
& \left.\frac{\partial T}{\partial r}\right|_{r=0}=0 \quad r=0 \quad t>0 \\
& -\left.k \frac{\partial T}{\partial r}\right|_{r=R}=q(t)=? \quad r=R \quad t>0 \\
& T(r, 0)=T_{0} \quad 0 \leq r \leq R \quad t=0
\end{aligned}
$$

Where: $k$ is the thermal conductivity in $\mathrm{W} / \mathrm{m} \mathrm{K}, \rho$ is the density in $\mathrm{kg} / \mathrm{m}^{3}, C p$ is the heat capacity at constant pressure in $\mathrm{J} /(\mathrm{kg} \mathrm{K}), q$ is the surface heat flux (unknown) in $\mathrm{W} / \mathrm{m}^{2}$ and $T_{0}$ is the initial probe temperature in ${ }^{\circ} \mathrm{C}$. The thermophysical properties used to simulate the thermal response of AISI 304 stainless steel were temperature-dependent [13]. 


\section{Results and Discussion}

The thermal histories measured during quenching of the conical-end probe with water at $60^{\circ} \mathrm{C}$ flowing at $0.2 \mathrm{~m} / \mathrm{s} \mathrm{and} \mathrm{an}$ initial probe temperature of $850^{\circ} \mathrm{C}$ are plotted in Fig. 4. Selected images extracted from the low frequency high-speed video for that test are shown in Fig. 5.

The first portion of the curves is horizontal because the probe is still inside the furnace. When the probe reached the immersion position, the cooling curves show evidence of the three stages of heat extraction. First, the temperature diminishes almost linearly due to the presence of the vapor film which formed as soon as the probe entered the quench medium (Fig. 5a). Subsequently, the vapor film collapses at the probe tip (Fig. 5b) and a wetting front is formed, which advances upwards along the probe surface. At approximately $12.3 \mathrm{~s}$, the wetting front passes at the position of the thermocouples (Fig. 5c) causing a significant temperature decrease in the cooling curves within a short period of time. While the wetting front travels, two regions can be identified: one located exactly at the wetting front, with bubbles of small diameter and fast nucleation frequency and, and a second one, below the wetting front, where the vapor bubbles are bigger and have a low nucleation frequency. Finally, when bubble formation ceases the probe, cools by pure convection and the temperature decreases smoothly until the water temperature is reached (Fig. 5d). It must be noted that the curve for TC2 shows a time lag with respect to the events at the surface.

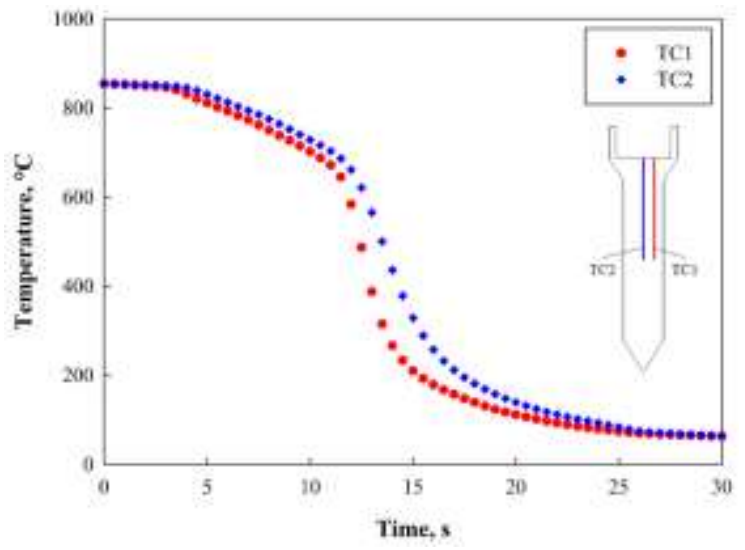

Fig. 4: Measured thermal histories during quenching of the conical-end probe with water at $60^{\circ} \mathrm{C}$ flowing at $0.2 \mathrm{~m} / \mathrm{s}$ and initial probe temperature of $850^{\circ} \mathrm{C}$.

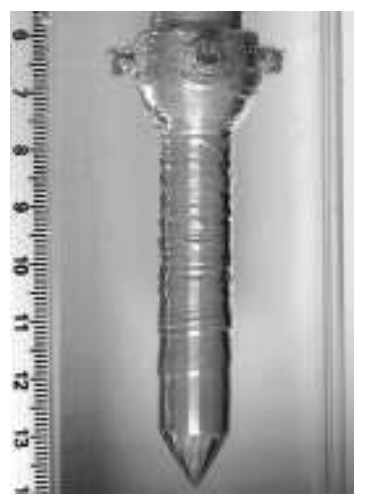

(a)

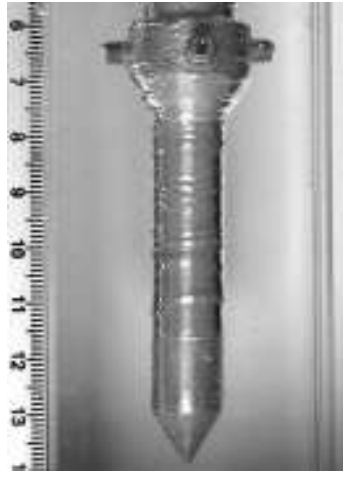

(b)

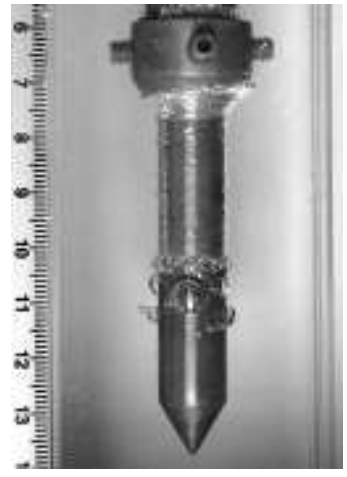

(c)

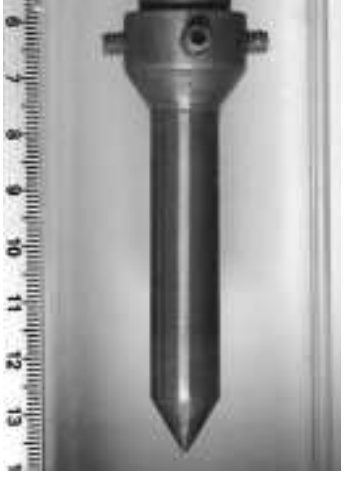

(d)

Fig. 5: Images of the probe surface during quenching with water at $60^{\circ} \mathrm{C}$ flowing at $0.2 \mathrm{~m} / \mathrm{s}$ and initial probe temperature of $850{ }^{\circ} \mathrm{C}$, at: a) $1.8 \mathrm{~s}, \mathrm{~b}) 2.9 \mathrm{~s}, \mathrm{c}) 12.3 \mathrm{~s}, \mathrm{~d}) 24.8 \mathrm{~s}$, with respect to time zero in the graph of Fig. 4.

The thermal history measured with TC1 was used to estimate the surface heat flux and the surface temperature, by numerically-solving the 1D-IHCP implemented in the WinProbe software [14]. In all cases, a value of $r=4$ was chosen ( $r$ being the number of future time steps) and a finite-difference mesh consisting of 15 nodes between the probe center and the 
radial thermocouple position and 5 nodes between the latter and the probe surface. The estimated surface heat flux history is plotted in Fig. 6.

Initially, the surface heat flux is nearly zero indicating that the probe was still in the furnace; once the probe was transported to the cooling position a slight increase in the heat flux is observed. After that, the surface heat flux remains approximately constant due to the presence the vapor film that covers all probe surface. When the probe temperature decreases below the Leidenfrost temperature, the vapor film collapses, and the surface heat flux increases until reaching a peak value $\left(-2.75 \mathrm{MWm}^{-2}\right)$ approximately at the time when the wetting front reaches the position of TC1. Later, heat extraction decreases as boiling becomes less apparent; afterwards, it decreases towards zero as the probe surface temperature reaches the water temperature during the pure convective stage.

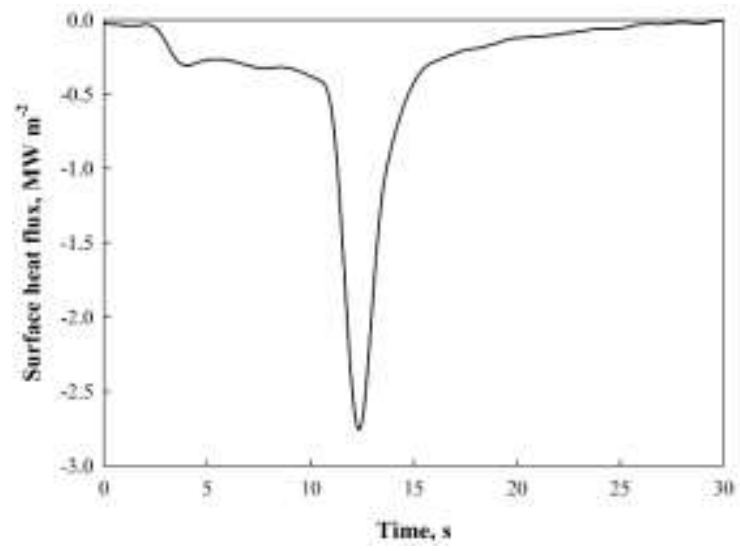

Fig. 6: Estimated surface heat flux history, at the probe mid-height, during quenching with water at $60^{\circ} \mathrm{C}$ flowing at $0.2 \mathrm{~m} / \mathrm{s}$ and initial probe temperature of $850^{\circ} \mathrm{C}$.

To estimate the wetting front velocity, its instantaneous position from the base of the cylindrical portion of the probe was measured frame by frame from the low-frequency videos, using the software Tracker. The resulting position-time data was then plotted as shown in Fig. 7. It is seen that the data may be fitted to a straight line with a high coefficient of determination. The latter indicates a very good fit and, therefore, a constant wetting front velocity $\left(4.18 \mathrm{~m} \mathrm{~s}^{-1}\right)$.

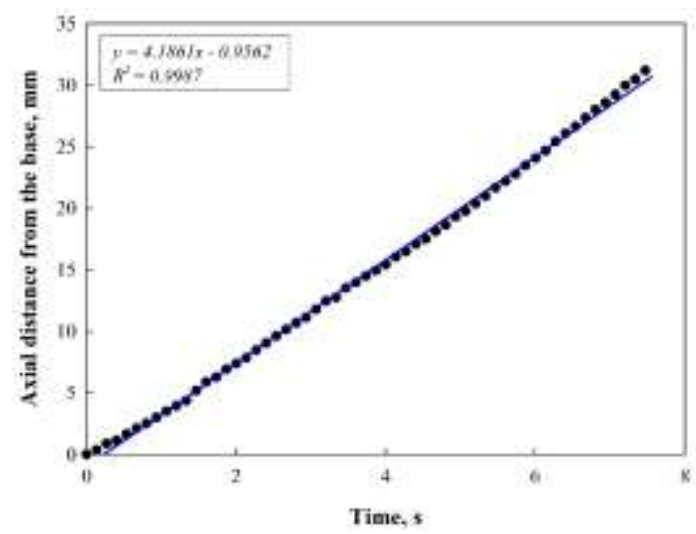

Fig. 7: Wetting front position-time data during quenching with water at $60^{\circ} \mathrm{C}$ flowing at $0.2 \mathrm{~m} / \mathrm{s}$ and initial temperature of $850{ }^{\circ} \mathrm{C}$. The line represents a linear regression.

An image extracted from the high-speed video-recordings is shown in Fig. 8. It may be noticed that bubbles at the wetting front were considerably smaller than the bubbles formed in the region below it. In the video-recordings it was observed that the lifecycle of the small bubbles was significantly smaller than that of the larger ones. Also, the former coalesced, creating larger bubbles that quickly departed from the probe surface. Below the wetting front, the bubbles grow and depart without influence of neighboring bubbles. They conserved a spheroidal shape until they reached their maximum size. After that, those bubbles began shrinking while slightly shifting from the nucleate site and, finally, they departed from 
the probe surface collapsing in the bulk flow, near the probe surface. This dynamic behavior is in good agreement with that reported by other researchers [5-10] and is related to the inverse boiling curve as the dynamics of the bubbles at or near the wetting front produce the maximum heat extraction.

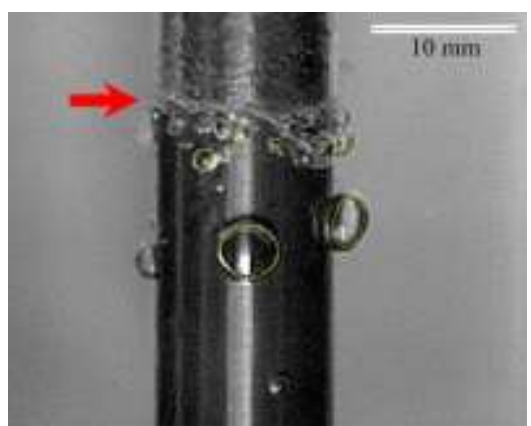

Fig. 8: Image of bubble size distribution bubble diameter is reached, (b) bubble starts departing from the surface and (c) bubble departs from the surface.

Images of a bubble below the wetting front are shown in Fig. 9. The images were extracted from a high-speed videorecording (30 $000 \mathrm{fps}$ ) and show a region near the thermocouples position. The bubble nucleating site was about $3 \mathrm{~mm}$ below the thermocouples position which in turn was approximately $3 \mathrm{~mm}$ below the wetting front. After a short period of rapid growth, as shown in Fig. 9 (a)-(f), the bubble reached its maximum size. As shown in images (g)-(i), while the bubble size decreased, its shape changed significantly. A concave deformation of the bubble was created at the interface, stretching the bubble (Fig. 9 (i)-(1)) until the bubble departing from the probe surface was completed (Fig. 9(j)). This deformation during the departure period was observed in almost all bubbles analyzed and could be explained by the condensation occurred in that region caused by the cold liquid coming from the subcooled bulk flow.

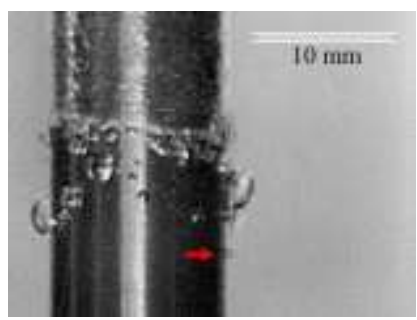

(a)

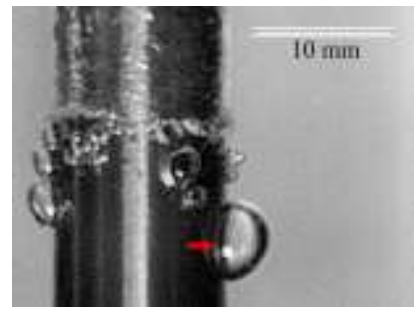

(e)

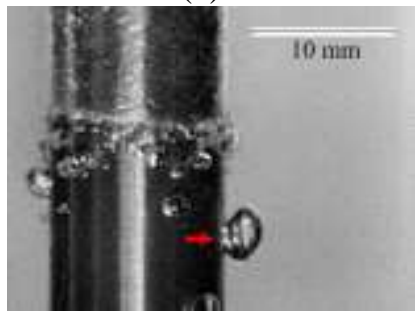

(i)

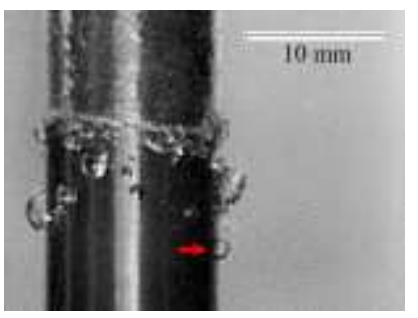

(b)

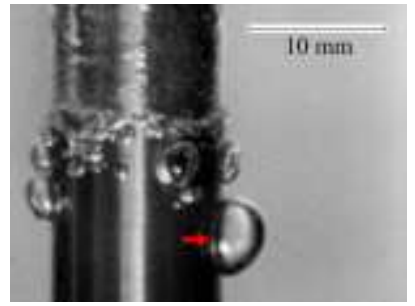

(f)

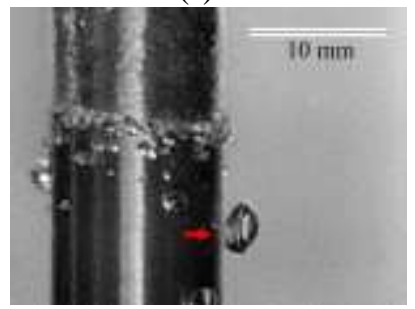

(j)

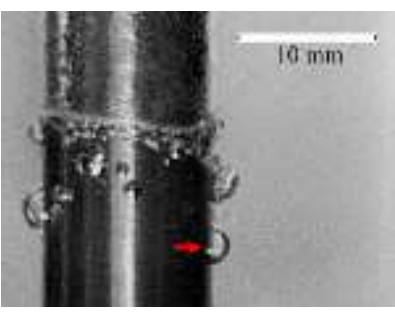

(c)

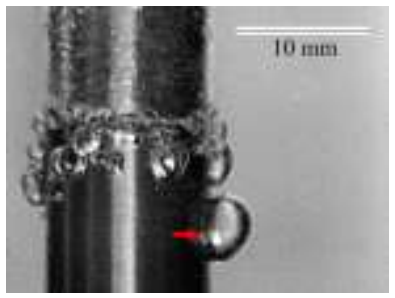

$(\mathrm{g})$

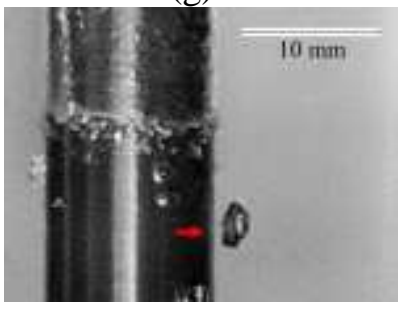

$(\mathrm{k})$

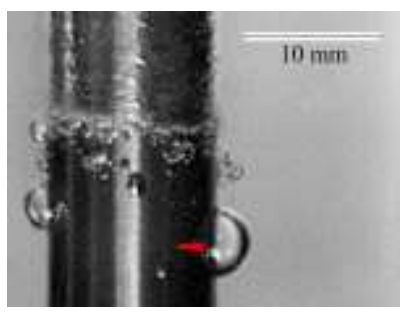

(d)

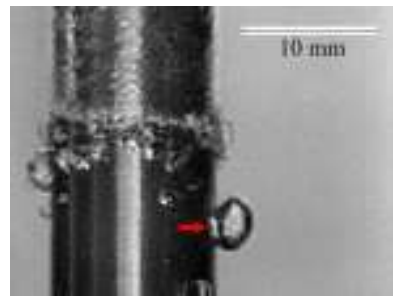

(h)

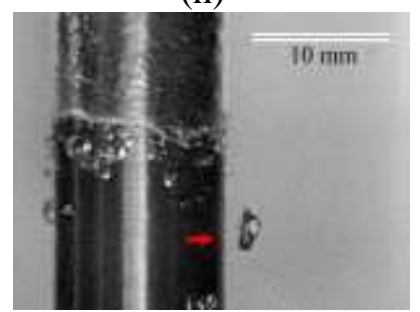

(1)

Fig. 9: Sequential images of bubble behavior beneath the wetting front during quenching with water at $60^{\circ} \mathrm{C}$ flowing at $0.2 \mathrm{~m} / \mathrm{s}$ and initial temperature of $850^{\circ} \mathrm{C}$. 
The mean bubble diameter was calculated by averaging the measurements of four Feret diameters (distance between opposing parallel tangents on the surface of the bubble [15]) and are plotted as a function of time in Fig. 11 for the bubble shown in Fig. 9. Shortly after the bubble embryo appeared at the probe surface, the bubble diameter increased rapidly and reached its maximum diameter $(4.0 \mathrm{~mm})$ at approximately $2000 \mu \mathrm{s}$. Later, the bubble size gradually decreased. At $4000 \mu \mathrm{s}$ the bubble began departing until it completely separated from the probe surface at $4900 \mu \mathrm{s}$.

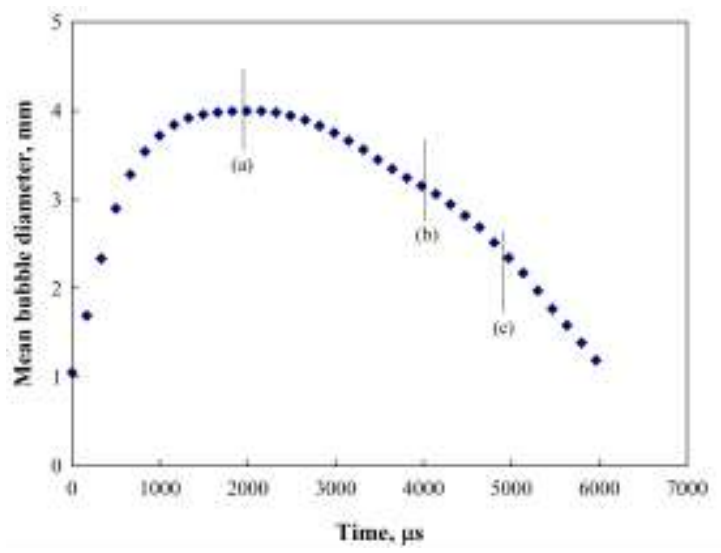

Fig. 10: Evolution of the mean bubble diameter for the bubble identified in Fig. 7. Letters in the plot indicate the time at which: (a) the maximum bubble diameter is reached, (b) bubble starts departing from the surface and (c) bubble departs from the surface. The time is measured with respect to the bubble nucleation.

\section{Conclusion}

In this study, an experimental investigation to correlate heat extraction with boiling phenomena at the liquid-probe interface during forced convective quenching of a steel probe in a laboratory-scale facility was conducted. Bubble dynamic characteristics at different regions of the probe were quite different. The wetting front is made up of a significant bubble population of small size and short lifetime. These bubbles rapidly grew and coalesced creating bigger bubbles that eventually departed from the probe surface and collapsed close to it. Bubbles formed below the wetting front were bigger and are spheroidal during most of their growing period. Before departing, these bubbles shrunk adopting an elongated shape and, after detaching from the probe surface, they collapsed in the bulk flow in the neighborhood of the probe.

\section{Acknowledgements}

The authors would like to thank Dr. José Enrique Guzman Vázquez for his support and assistance during experiments with the high-speed camera. One of the authors (Roberto Cruces) gratefully acknowledges the financial support from PAEP to attend 5th International Conference on Heat Transfer and Fluid Flow (HTFF'18) and from CONACYT (No. de becario: 286914) for the scholarship granted for his Doctoral studies.

\section{References}

[1] D. Mackenzie, "History of Quenching," International Heat Treatment \& Surface Engineering, vol. 2, no. 2, pp. 6873, 2008.

[2] G. E. Totten, C. E. Bates and N. A. Clinton, "Handbook of Quenchants and Quenching Technology," ASM International, 1993.

[3] C. H. Gür and C. Şimşir, "Simulation of Quenching: A Review," Materials Performance and Characterization, vol. 1, no. 1, pp. 1-37, 2012.

[4] H. Tensi, A. Stich, and G. Totten, "Fundamentals about quenching by submerging," in Proc. of the International HeatTreating Conference: Equipment and Processes, ASM International, Materials Park, OH, pp. 243-251, 1994.

[5] J. F. Klausner, R. Mei, D. M. Bernhard, L. Z. Zeng, "Vapor bubble departure in forced convection boiling," International Journal of Heat and Mass Transfer, vol. 36, no. 3, pp. 651-662, 1993.

[6] E. L. Bibeau, M. Salcudean, "A study of bubble ebullition in forced-convective subcooled nucleate boiling at low pressure," International Journal of Heat and Mass Transfer, vol. 37, no. 15, pp. 2245-2259, 1994. 
[7] V. Prodanovic, D. Fraser and M. Salcudean, "Bubble behavior in subcooled flow boiling of water at low pressures and low flow rates," International Journal of Multiphase Flow, vol. 28, no. 1, pp. 1-19, 2002.

[8] R. Maurus, V. Ilchenko and T. Sattelmayer, "Study of the bubble characteristic and the local void fraction in subcooled flow boiling using digital imaging and analysing techniques," Exp. Therm. Fluid Sci., vol. 26, pp. 147-155, 2002.

[9] R. Situ, Y. Mi, M. Ishii, M. Mori, "Photographic study of bubble behaviors in forced convection subcooled boiling," International Journal of Heat and Mass Transfer, vol. 47, no. 17-18, pp. 3659-3667, 2004.

[10] Y. Cao, Z. Kawara, T. Yokomine, T. Kunugi, "Visualization study on bubble dynamical behavior in subcooled flow boiling under various subcooling degree and flowrates," International Journal of Heat and Mass Transfer, vol. 93, pp. 839-852, 2016.

[11] R. Cruces, B. Hernández and E. I. Durán, "Re-wetting behavior and heat extraction during laboratory-scale quenching experiments using two probe geometries," Heat Treat 2017: in Proc. of the 29th ASM Heat Treating Society Conference, ASM International, Columbus, Ohio, USA, pp. 8, 2017.

[12] J. Beck, B. Litkouhi and C. R. St. Clair, "Efficient Sequential Solution of the Nonlinear Inverse Heat Conduction Problem," Numerical Heat Transfer, vol. 5, no. 3, pp. 275-286, 1982.

[13] K. C. Mills, Y. Su, Z. Li, and R. F. Brooks, "Equations for the Calculation of the Thermo-physical Properties of Stainless Steel”, ISIJ International, vol. 44, no. 10, pp. 1661-1668, 2004.

[14] L. Meekisho, B. Hernández-Morales, J. S. Téllez-Martínez and X. Chen, "Computer-aided cooling curve analysis using WinProbe," Int. J. Materials and Product Technology, vol. 24, no. 1-4, pp. 55-169, 2005.

[15] H. Merkus, Particle Size Measurements: Fundamentals, Practice, Quality. Springer, 2009, pp. 15. 